\title{
KELAYAKAN ABU TERBANG PLTU BUNTOI SEBAGAI CAMPURAN BETON GEOPOLIMER
}

\section{FEASIBILITY OF FLYING ASH OF PLTU BUNTOI AS A GEOPOLIMARY CONCRETE MIXTURE}

\author{
Dadang Suriyana $^{* 1}$, Liliana $^{2}$, Okta Meilawaty ${ }^{3}$ \\ ${ }^{1}$ Mahasiswa, Program Studi Teknik Sipil, Fakultas Teknik, Universitas Palangka Raya \\ 2,3 Dosen, Program Studi Teknik Sipil, Fakultas Teknik, Universitas Palangka Raya \\ *Korespondensi: dadangengineer50@gmail.com
}

\begin{abstract}
ABSTRAK
Bahan dasar utama yang dibutuhkan untuk pembuatan material geopolimer ini adalah bahan-bahan yang banyak mengandung unsur-unsur silika dan aluminia. Pengujian tahap 1 dilakukan untuk mengetahui pasta geopolimer dengan kuat tekan maksimum pada perbandingan $\mathrm{NaOH}$ terhadap $\mathrm{Na} 2 \mathrm{SiO} 3$ sebesar 1;1,5;2;2,5. Pengujian tahap 2 dilakukan dengan menggunakan pasta geopolimer dengan kuat tekan paling tinggi yaitu pada perbandingan $\mathrm{NaOH}$ terhadap $\mathrm{Na} 2 \mathrm{SiO} 3$ sebesar 2,5 dengan kuat tekan 22,56 MPa. Berdasarkan hasil pengujian kuat tekan diperoleh kuat tekan maksimum pada umur 28 hari sebesar 7,64 MPa. Hasil kuat tekan beton jauh lebih rendah dibandingkan dengan kuat tekan pasta, hal itu menunjuk an bahwa pasta tidak terlalu mengikat dengan agregat. Hal itu dibuktikan dengan hasil kuat tekan beton konvensional yang jauh lebih tinggi dibandingkan dengan beton geopolimer menggunakan agregat yang sama. Dengan hasil kuat tekan maksimum pada umur 28 hari sebesar 29,51 MPa.
\end{abstract}

Kata Kunci: Abu Terbang, Beton Geopolimer, Geopolimer, $\mathrm{NaOH}, \mathrm{Na}_{2} \mathrm{SiO}_{3}$.

\begin{abstract}
The main basic ingredients needed for the manufacture of this geopolymer material are materials that contain a lot of silica and aluminia elements. The 1st stage test was carried out to determine the geopolymer paste with the maximum compressive strength at the ratio of $\mathrm{NaOH}$ to $\mathrm{Na2SiO3} \mathrm{of} 1 ; 1.5 ; 2 ; 2.5$. The second stage of testing was carried out using a geopolymer paste with the highest compressive strength, namely the ratio of $\mathrm{NaOH}$ to Na2SiO3 of 2.5 with a compressive strength of $22.56 \mathrm{MPa}$. Based on the results of the compressive strength test, the maximum compressive strength at the age of 28 days is $7.64 \mathrm{MPa}$. The results of the compressive strength of concrete are much lower than the compressive strength of the paste, it shows that the paste does not bind too much with the aggregate. This is evidenced by the results of the compressive strength of conventional concrete which is much higher than that of geopolymer concrete using the same aggregate. With the results of the maximum compressive strength at the age of 28 days is $29.51 \mathrm{MPa}$.
\end{abstract}

Keywords: Fly Ash, Geopolymer, Geopolymer Concrete, $\mathrm{NaOH}, \mathrm{Na}_{2} \mathrm{SiO}_{3}$. 


\section{PENDAHULUAN}

Beton pada saat ini merupakan jenis konstruksi yang sangat diminati, dan semen Portland adalah unsur yang paling penting untuk membuat campuran beton. Di Indonesia sendiri pembangunan infrastruktur banyak menggunakan konstruksi beton. Dengan demikian maka produksi semen di Indonesia sangat meningkat dan $\mathrm{CO}_{2}$ hasil pembakaran semen pun semakin meningkat dan menimbulkan masalah global.

Selain itu masalah global pada saat ini adalah pencemaran lingkungan yang diakibatkan oleh limbah pembakaran batu bara yang berupa abu terbang. Abu terbang termasuk dalam limbah berbahaya yang mengandung oksida logam berat yang bias mengalami pelarutan secara alami dan dapat mencemari lingkungan. Saat ini pembangkit listrik lebih banyak menggunakan batu bara sebagai bahan utama dan akan lebih banyak menimbulkan limbah hasil pembakaran. Salah satu pembangkit listrik yang menggunakan batu bara adalah PLTU Buntoi yang menghasilkan abu terbang dari hasil pembakaran. Limbah tersebut sangat potensial untuk dijadikan bahan pengganti semen pada campuran beton. Peneliti pada saat ini banyak menggunakan abu terbang sebagai bahan dasar penelitian. Tion (2019) menggunakan abu terbang PLTU Buntoi sebagai bahan pengganti semen sebagian dengan komposisi 2,5\%, 5\%, 7,5\%, $10 \%$ namun belum menghasilkan kuat tekan yang maksimum. Sementara itu Manuhae, Sumajouw dan Windah (2014) melakukan penelitian 100\% tanpa semen dengan teknologi geopolimer, penelitian tersebut menggunakan abu terbang tipe $\mathrm{F}$ yang berasal dari PLTU Amurang dengan konsentrasi $\mathrm{NaOH}$ 8M yang menghasilkan kuat tekan beton 27,462 MPa. Ekaputri dan Triwulan (2013) menggunakan abu terbang tipe $\mathrm{F}$ dari PLTU Paiton dengan konsentrasi $\mathrm{NaOH}$ sebesar 8M14M. Berdasarkan hasil beberapa penelitian diatas maka akan dilakukan penelitian menggunakan abu terbang PLTU Buntoi dengan $100 \%$ tanpa menggunakan semen dengan konsentrasi $\mathrm{NaOH}$ sebesar $8 \mathrm{M}$ yang diharapkan akan menhasilkan kuat tekan beton maksimal dan dapat memanfaatkan limbah pencemaran hasil pembakaran PLTU.

Pengujian material dilakukan untuk mengetahui nilai mutu dari bahan yang digunakan. Tujuan penelitian ini adalah untuk mengetahui komposisi pasta geopolymer dengan kuat tekan maksimum, untuk mengetahui kuat tekan beton geopolimer, untuk mengetahui perbandingan beton geopolymer dan konvensional, untuk mengetahui interaksi semen geopolymer dengan bahan pembentuk beton geopolimer lainnya.

\section{TINJAUAN PUSTAKA}

\section{Semen}

Berdasarkan SNI 15-2049-2004 semen diartikan sebagai material yang dihasilkan dari proses penggilingan kalsium silikat yang bersifat hidrolis dengan bahan tambah lainnya yang berupa kalsium sulfat. Bahan dasar penyusun semen adalah yang mengandung kapur, silika dan oksida besi. Semen menurut jenis terbagi atas OPC, PPC, dan PCC.

\section{Geopolimer}

Geopolimer adalah teknologi yang 100\% tanpa menggunakan semen Portland atau material yang terbentuk dari hasil polimerisasi silika, alumina dan oksigen. Geopolimer saat ini banyak dikembangkan untuk pembuatan beton, karena dapat menghasilkan kuat tekan beton yang cukup tinggi dan tahan terhadap asam. Selain itu jika dibandingkan dengan semen Portland, semen geopolymer lebih ramah lingkungan dan hemat energi.

\section{Abu Terbang}

Abu terbang (fly ash) merupakan limbah dari hasil pembakaran batu bara yang digunakan pada Pembangkit Listrik Tenaga Uap (PLTU) dengan ukuran partikel berkisar antara 5-100 $\mu \mathrm{m}$. Abu batu bara yang merupakan limbah dari proses pembakaran pada pembangkit tenaga listrik tersebut dapat berupa abu terbang, abu dasar dan lumpur flue gas desulfurization. Produksi abu terbang batu bara (fly ash) didunia terutama di Indonesia akan terus bertambah seiring dengan bertambahnya penggunaan batu bara pada pembangkit listrik dalam menghasilkan energi.

\section{Alkali Aktivator}

Menurut Palomo, Grutzeck, dan Blanco (1999) larutan alkali aktivator yang dapat memberikan kuat tekan dengan baik adalah kombinasi antara $\mathrm{NaOH}$ dan sodium silikat atau kombinasi antara $\mathrm{KOH}$ dan potassium silikat. Larutan alkali aktivator merupakan larutan yang dibutuhkan untuk memungkinkan terjadinya reaksi polimerisasi monomer alumina dan silika. Larutan alkali berasal 
dari logam alkali yang dapat larut, yang pada umumnya adalah larutan berbasis natrium atau kalium. Berdasarkan penelitian yang dilakukan oleh Palomo, Grutzeck, dan Blanco, penggunaan larutan natrium hidroksida $(\mathrm{NaOH})$ dan larutan natrium silikat $\left(\mathrm{Na}_{2} \mathrm{SiO}_{3}\right)$ dapat menghasilkan kekuatan tekan yang tinggi. Kuat tekan dapat mencapai hingga $60 \mathrm{MPa}$ jika di-curing pada suhu $85^{\circ} \mathrm{C}$ selama 5 jam.

\section{Keaslian Penelitian}

Tabel 1. Keaslian Penelitian

\begin{tabular}{|c|c|c|c|}
\hline Peneliti & $\begin{array}{l}\text { Fly } \\
\text { ash }\end{array}$ & $\mathrm{NaOH}$ & $\begin{array}{l}\text { Kuat } \\
\text { tekan } \\
\text { (MPa) }\end{array}$ \\
\hline $\begin{array}{l}\text { Windah, } \\
\text { Sumajouw, } \\
\text { Manuahe, } \\
2014\end{array}$ & $\begin{array}{l}\text { Tipe } \\
\text { F }\end{array}$ & $8 \mathrm{M}$ & 27,462 \\
\hline Septia, 2011 & $\begin{array}{l}\text { Tipe } \\
\text { F }\end{array}$ & $8 \mathrm{M}$ & $\sqrt{ }$ \\
\hline Ferdy, 2010 & $\begin{array}{l}\text { Tipe } \\
\text { F }\end{array}$ & $\sqrt{ }$ & 43,77 \\
\hline $\begin{array}{l}\text { Yuanda, } \\
\text { fadli, } \\
\text { drastinawati, } \\
2015\end{array}$ & Tipe $\mathrm{f}$ & $14 \mathrm{M}$ & $\begin{array}{l}7,56 \\
\mathrm{mpa}\end{array}$ \\
\hline $\begin{array}{l}\text { Ekaputri dan } \\
\text { Triwulan, } \\
2013\end{array}$ & $\begin{array}{l}\text { Tipe } \\
\text { F }\end{array}$ & $8-14 \mathrm{M}$ & $\begin{array}{l}51,3 \\
\text { mpa }\end{array}$ \\
\hline $\begin{array}{l}\text { Suriyana, } \\
2019\end{array}$ & $\begin{array}{l}\text { Tipe } \\
\text { C }\end{array}$ & $8 \mathrm{M}$ & $\sqrt{ }$ \\
\hline
\end{tabular}

Sumber : Penelitian Terdahulu

\section{METODE PENELITIAN}

\section{Material Geopolimer}

1. Abu terbang yang digunakan berasal dari PLTU Buntoi.

2. Agregat kasar yang digunakan adalah batu pecah yang berasal dari Mandiangin.

3. Agregat halus yang digunakan adalah pasir putih yang berasal dari Tangkiling.

4. Alkali activator yang digunakan adalah $\mathrm{NaOH}$ dan $\mathrm{Na}_{2} \mathrm{SiO}_{3}$.

\section{Pemeriksaan Sifat Fisik Agregat}

1. Pemeriksaan Berat Volume.

2. Pemeriksaan Analisa Saringan.

3. Pemeriksaan Kadar Air.

4. Pemeriksaan Berat Jenis.
5. Pemeriksaan Kadar Lumpur.

6. Pemeriksaan Keausan.

\section{Proporsi Campuran Pasta Geopolimer}

Pasta geopolymer terlebih dahulu dilakukan trial mix untuk mendapatkan komposisi kuat tekan maksimum dengan menggunakan benda uji berukuran 20x40 $\mathrm{mm}^{3}$. Pada pembuatan pasta geopolymer $\mathrm{NaOH}$ yang digunakan yaitu sebesar 8M atau sebanyak 320 gram. Perbandingan antara $\mathrm{Na}_{2} \mathrm{SiO}_{3}$ (Sodium Silikat) dengan $\mathrm{NaOH}$ (Sodium Hidroksida) adalah $1 ; 1,5 ; 1 ; 2,5$. Abu terbang yang digunakan sebanyak 100 gram dengan perbandingan antara abu terbang dan alkali activator adalah 55\%: $45 \%$.

Tabel 2. Rekapitulasi Komposisi Pasta Geopolimer

\begin{tabular}{ccccc}
\hline No & $\begin{array}{c}\mathrm{Na}_{2} \mathrm{SiO}_{3} \\
\text { /NaOH }\end{array}$ & $\begin{array}{c}\mathbf{N a O H} \\
\text { (gram) }\end{array}$ & $\begin{array}{c}\mathrm{Na}_{2} \mathrm{SiO}_{3} \\
(\text { gram) }\end{array}$ & $\begin{array}{c}\text { Jumlah } \\
\text { Sampel }\end{array}$ \\
\hline 1 & 1 & 40,9 & 40,9 & 6 Buah \\
2 & 1,5 & 32,73 & 49,09 & 6 Buah \\
3 & 2 & 27,27 & 54,54 & 6 Buah \\
4 & 2,5 & 23,37 & 58,43 & 6 Buah \\
\hline \multicolumn{5}{l}{ Sumber : Hasil Perhitungan (2020) }
\end{tabular}

\section{Pembuatan Pasta Geopolimer}

Larutan $\mathrm{NaOH}$ yang berbentuk padat terlebih dahulu dicairkan, dimasukan kedalam gelas ukur kemudian ditambahkan air hingga benar-benar tenggelam, setelah itu dimasukan kedalam labu ukur dan dilihat apakah sudah mencapai garis batas pada labu ukur, jika belum maka ditambahkan air hingga mencapai batas pada labu ukur. Larutan $\mathrm{NaOH}$ yang telah cair didiamkan selama 24 jam agar mencapai suhu ruangan. Kemudian dicampurkan dengan Larutan $\mathrm{Na}_{2} \mathrm{SiO}_{3}$, diaduk hingga tercampur rata. Kemudian abu terbang dimasukan dan diaduk menggunakan mixer agar tercampur rata. Adonan pasta tersebut dimasukan kedalam cetakan silinder $20 \times 40 \mathrm{~mm}^{3}$ dan ditutup menggunakan plastik agar tidak terjadi penguapan, dan dilakukan curing pada suhu $60^{\circ} \mathrm{C}$ selama 24 jam.

\section{Mix Design Campuran Beton}

Beton konvensional direncanakan dengan mutu beton $\mathrm{fc}^{\prime}=30 \mathrm{MPa}$ dengan menggunakan metode SNI 03-2834-1993. Perhitungan campuran beton geopolimer menggunakan perbandingan $\mathrm{Na}_{2} \mathrm{SiO}_{3} / \mathrm{NaOH}$ yang hasil kuat tekannya paling 
tinggi, yaitu 2,5 dengan kuat tekan 22,56 MPa pada umur 28 hari.

Tabel 3. Rekapitulasi Campuran Beton

\begin{tabular}{clcccc} 
No & Uraian & Vol. & Kon. & Geo. & Sat. \\
\hline 1 & Semen & 0,006 & 2,584 & - & $\mathrm{kg}$ \\
2 & Air & 0,006 & 1,068 & - & $\mathrm{lt}$ \\
3 & Batu & 0,006 & 4,053 & 2,939 & $\mathrm{~kg}$ \\
4 & Pasir & 0,006 & 5,173 & 5,878 & $\mathrm{~kg}$ \\
5 & Fly Ash & 0,006 & - & 2,611 & $\mathrm{~kg}$ \\
6 & $\mathrm{NaOH}$ & 0,006 & - & 0,611 & $\mathrm{~kg}$ \\
7 & $\mathrm{Na}_{2} \mathrm{SiO}_{3}$ & 0,006 & - & 1,526 & $\mathrm{~kg}$ \\
\hline
\end{tabular}

\section{Pengujian Beton}

1. Pengujian Workability (Slump Beton).
2. Pengujian Berat Volume (Berat Volume Beton Segar).

3. Pengujian Kuat Tekan Pasta Geopolimer.

4. Pengujian Kuat Tekan Beton Konvensional dan Geopolimer.

\section{ANALISIS DAN PEMBAHASAN}

\section{Kuat Tekan Pasta Geopolimer}

Dari hasil kuat tekan pasta geopolimer diperoleh hasil kuat tekan yang paling tinggi pada perbandingan $\mathrm{Na}_{2} \mathrm{SiO}_{3}$ dengan $\mathrm{NaOH}=2,5$ pada umur 28 hari dengan nilai kuat tekan tekan 22,56 MPa. Maka dipilih perbandingan $\mathrm{Na}_{2} \mathrm{SiO}_{3}$ dengan $\mathrm{NaOH}$ yang kuat tekan pasta paling tinggi untuk selanjutnya dilakukan pembuatan beton geopolimer.

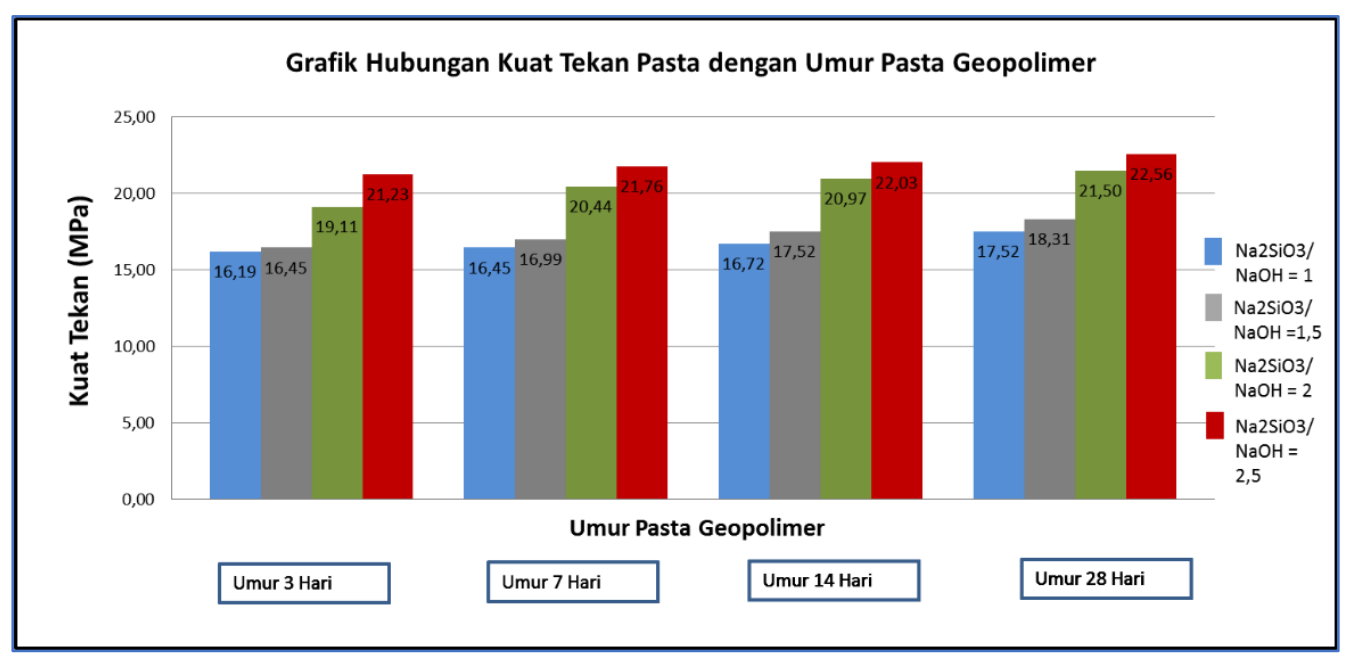

Gambar 1. Grafik Hubungan Kuat Tekan Pasta Geopolimer dengan Umur Pasta Geopolimer

\section{Karakteristik Agregat}

\section{Karakteristik Agregat Kasar}

1. Berat Volume yang dihasilkan sebesar 1,372 $\mathrm{kg} / \mathrm{liter}$.

2. Analisis Saringan yang dihasilkan pada modulus kehalusan sebesar $6,5 \%$.

3. Kadar Air dihasilkan adalah $2,63 \%$.

4. Berat Jenis yang dihasilkan adalah 2,52 $\mathrm{kg} / \mathrm{m} 3$.

5. Kadar Lumpur yang dihasilkan adalah $2,61 \%$.

6. Keausan yang dihasilkan adalah $34,50 \%$.

\section{Karakteristik Agregat Halus}

1. Berat volume yang dihasilkan pada kondisi padat $1,692 \mathrm{~kg} / \mathrm{liter}$.

2. Analisis Saringan yang dihasilkan pada modulus kehalusan sebesar 3,38\%.

3. Kadar Air yang diperoleh sebesar $0,08 \%$.

4. Berat Jenis yang dihasilkan adalah 2,50 $\mathrm{kg} / \mathrm{m} 3$.

5. Kadar Lumpur yang dihasilkan adalah $22,24 \%$.

\section{Pemeriksaan Slump Beton}

1. Beton geopolimer menghasilkan slump sebesar $1,5 \mathrm{~cm}$. 
2. Beton konvensional menghasilkan slump sebesar $3,5 \mathrm{~cm}$.

\section{Pemeriksaan Beton Segar}

1. Beton geopolimer menghasil berat volume beton segar sebesar $2452,23 \mathrm{~kg} / \mathrm{m} 3$.

2. Beton konvensional menghasilkan berat volume beton segar sebesar 2390,00 kg/m3.

\section{Kuat Tekan Beton}

Dari hasil pengujian diperoleh hasil sebagai sebagai berikut.

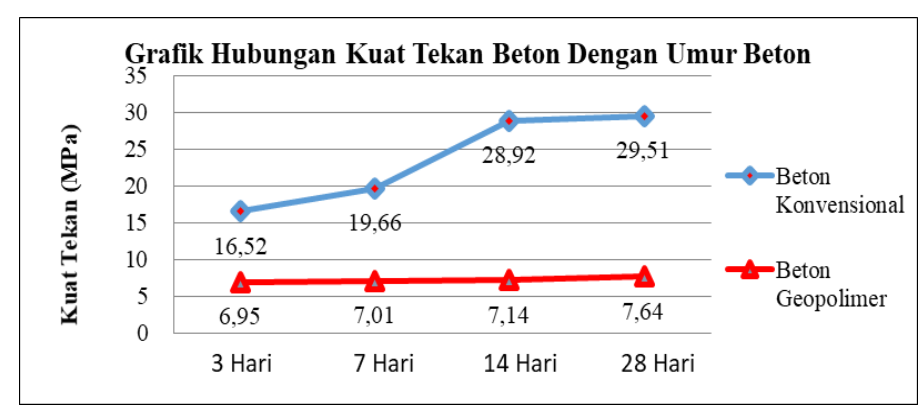

Gambar 2. Grafik Hubungan Kuat Tekan Beton Dengan Umur Beton

Tabel 4. Hasil Pengujian Kuat Tekan Beton

\begin{tabular}{|c|c|c|c|c|c|}
\hline \multirow{2}{*}{ No } & \multicolumn{2}{|c|}{ Tanggal } & \multirow{2}{*}{$\begin{array}{l}\text { Umur } \\
\text { (Hari) }\end{array}$} & \multicolumn{2}{|c|}{ Kuat Tekan Rata-Rata (Mpa) } \\
\hline & Buat & Test & & Konvensional & Geopolimer \\
\hline 1 & $3 / 3 / 2020$ & $9 / 3 / 2020$ & 3 & 16,52 & 6,95 \\
\hline 2 & $28 / 2 / 2020$ & $11 / 3 / 2020$ & 7 & 19,66 & 7,01 \\
\hline 3 & $10 / 2 / 2020$ & $25 / 2 / 2020$ & 14 & 28,92 & 7,14 \\
\hline 4 & $7 / 2 / 2020$ & $6 / 3 / 2020$ & 28 & 29,51 & 7,64 \\
\hline
\end{tabular}

Sumber : Hasil Perhitungan (2020)

Pengujian kuat tekan dilakukan pada benda uji silinder dengan ukuran 100x200 $\mathrm{mm}^{3}$ pada umur 3,7,14,28 hari dengan hasil yang didapat dalam bentuk Kilo Newton (KN) yang dikonversi dalam satuan Mega Pascal (MPa). Dari hasil pengujian kuat tekan beton geopolimer diperoleh hasil paling tinggi 7,64 MPa pada umur 28 hari. Hasil kuat tekan beton jauh lebih rendah dibandingkan dengan kuat tekan pasta. Berdasarkan Gambar 3. salah satu faktor yang mempengaruhi hasil tersebut karena pasta yang tidak terlalu mengikat dengan agregat, sehingga hasil kuat tekan beton yang dihasilkan rendah. Jika dibandingkan dengan penelitian terdahulu hasil yang diperoleh jauh lebih rendah dikarenakan abu terbang yang digunakan pada penelitian ini lebih sedikit mengandung silika dan alumina.

Jika dilihat dari karakteristik agregat yang digunakan, agregat sudah memenuhi standar untuk menghasilkan kuat tekan beton yang tinggi. Maka hasil yang rendah tersebut sangat dipengaruhi oleh material pembentuk pasta sebagai pengikat dengan agregat.

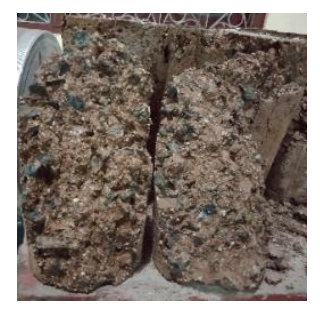

Gambar 3. Pola Retak Beton Geopolimer

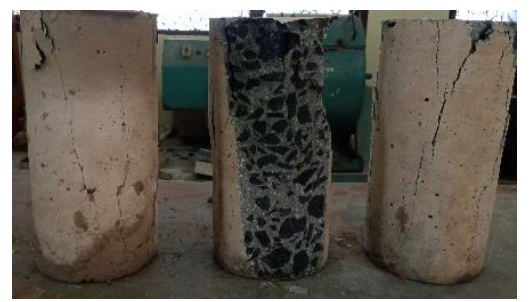

Gambar 4. Pola Retak Beton Konvensional

Dari hasil pengujian kuat tekan beton konvensional diperoleh hasil paling tinggi 29,51 MPa pada umur 28 hari. Hasil yang diperoleh masih dibawah dari kuat tekan rencana sebesar $30 \mathrm{MPa}$. Hasil kuat tekan beton rendah dikarenakan agregat kasar yang digunakan tidak memenuhi standar untuk beton $30 \mathrm{MPa}$, tetapi hasil kuat tekan beton jauh lebih tinggi dibandingkan standar kelas beton untuk agregat yang dipakai, agregat kasar yang digunakan masuk dalam beton kelas II dengan kuat tekan maksimum $19 \mathrm{MPa}$. 
Kelayakan Abu Terbang .., Dadang Suriyana ${ }^{(1)}$, Liliana $^{(2)}$, Okta Meliawaty ${ }^{(3)}$

\section{PENUTUP}

\section{Kesimpulan}

Berdasarkan hasil penelitian dan pembahasan yang telah diuraikan dalam "Kelayakan Abu Terbang PLTU Buntoi Sebagai Campuran Beton Geopolimer" ini disimpulkan beberapa hal sebagai berikut :

1. Untuk menghasilkan kuat tekan pasta geopolimer yang maksimal komposisi yang diperlukan adalah fly ash sebesar 100 gram, alkali aktivator yang terdiri dari $\mathrm{NaOH}$ sebesar 23,37 gram dan $\mathrm{Na} 2 \mathrm{SiO} 3$ sebesar 58,43gram.

2. Dari hasil pengujian diperoleh hasil kuat tekan pasta geopolimer yang paling tinggi sebesar $22,56 \mathrm{MPa}$, yang dihasilkan pada umur 28 hari dengan perbandingan $\mathrm{NaOH}$ terhadap $\mathrm{Na} 2 \mathrm{SiO} 3$ sebesar 2,5.

3. Dari hasil pengujian diperoleh hasil kuat tekan beton geopolimer paling tinggi sebesar 7,64 MPa pada umur 28 hari dan hasil kuat tekan beton konvensional paling tinggi sebesar 29,51 MPa pada umur 28 hari. Beton geopolimer memiliki hasil kuat tekan yang jauh lebih rendah dibandingkan dengan kuat tekan beton konvensional yang diakibatkan karena pasta pada beton geopolimer yang tidak terlalu mengikat pada agrgeat.

4. Interaksi yang terjadi antara semen geopolimer berbahan abu terbang terhadap material pembentuk beton lainnya tidak terjadi interaksi yang baik, semen tidak terlalu mengikat terhadap agregat hal tersebut dibuktikan dengan hasil kuat tekan pasta yang tinggi yaitu sebesar 22,56 MPa, tetapi setelah dicampur dengan agregat hasil kuat tekan beton menjadi turun yaitu sebebsar 7,64 MPa. Hasil tersebut menunjukan bahwa abu terbang yang digunakan masih sedikit mengandung silika dan alumina.

\section{Saran}

Setelah melakukan penelitian ini, dapat disampaikan beberapa saran sebagai berikut:

1. Penelitian ini masih bisa untuk diadakan penelitian kembali dengan jenis fly ash yang sama dengan meninjau kembali pengaruh konsentrasi alkali altivator agar penggunaannya lebih maksimal.

2. Jika dilakukan penelitian lanjutan disarankan agar memperhatikan modulus kehalusan pasir yang lebih baik, agar menghasilkan kuat tekan yang lebih tinggi.

\section{DAFTAR PUSTAKA}

Davidovits, J, (1994), Membakar 1 Ton Semen Sama Dengan Menghasilkan 1 Ton Karbondioksida. Prancis.

Davidovits, J., (1970), Beton Geopolimer. Prancis.

Davidovits, J., (2012), Aplikasi Geopolimer Berdasarkan Rasio Si/Al. Prancis.

Ekaputri, J.J. \& Triwulan, (2013), Sodium Sebagai Aktivator Fly Ash, Trass dan Lumpur Sidoarjo Dalam Beton Geopolimer. Fakultas Teknik Institut Teknologi Sepuluh Nopember.

Ferdy., (2010), Pengaruh Temperatur Dan Waktu Curing Terhadap Kuat Tekan Pasta Geopolimer Berbahan Dasar Abu Terbang. Fakultas Teknik Universitas Indonesia.

Liliana, S., \& Meilawaty, O., (2018), Komposisi Kimia Fly Ash PLTU Buntoi Kabupaten Pulang Pisau. Palangka Raya.

Meilawaty, O., (2017), Buku Panduan Panduan Praktikum Beton. Fakultas Teknik Universitas Palangka Raya.

Mulyono, T., (2004), Teknologi Beton. Yogyakarta.

Septia, P., (2011), Studi Literatur Pengaruh Konsentrasi $\mathrm{NaOH}$ dan Rasio NaOH:Na2SO3, Rasio Air/Prekusor, Suhu Curing dan Jenis Prekursor Terhadap Kuat Tekan Beton Geopolimer. Fakultas Teknik Universitas Indonesia.

Sumajouw \& Dapas, (2012), Penggunaan Sodium Hidroksida dan Sidium Silikat. Manado.

Sukirman, S., (2003), Pengertian Agregat. Palembang.

Tion, F., (2019), Pemanfaatan Abu Batu Bara Sebagai Bahan Campuran Beton Pada Konstruksi Bangunan. Fakultas Teknik Universitas Palangka Raya.

Windah, Sumajouw, \& Manuahe, (2014), Kuat Tekan Beton Geopolymer Berbahan Dasar Abu Terbang (Fly Ash), Fakultas Teknik Universitas Sam Ratulangi.

Winter \& George, (1993), Material Penyusun Semen. Inggris. 
Kelayakan Abu Terbang .., Dadang Suriyana ${ }^{(1)}$, Liliana $^{(2)}$, Okta Meliawaty ${ }^{(3)}$

Yuanda, Fadli, \& Drastinawati, (2015), Pemanfaatan Limbah Abu Terbang (Fly Ash) Sebagai Bahan Pembuatan Beton Geopolimer. Fakultas Teknik Universitas Riau. 